\title{
Artificial Intelligence Approach to Secure Pension Fund
}

\author{
Safwat Saadeldin ${ }^{1}$, Hegazy Zaher ${ }^{2}$, \\ Naglaa Ragaa ${ }^{3}$ and Heba Sayed ${ }^{4}$ \\ ${ }^{1}$ PhD Candidate in Operations Research, faculty of \\ graduate studies for statistical research, Cairo \\ University, Egypt \\ ${ }^{2}$ Professor Doctor in Mathematical statistics, \\ faculty of graduate studies for statistical research, \\ Cairo University, Egypt \\ ${ }^{3}$ Professor in Operations Research, faculty of \\ graduate studies for statistical research, Cairo \\ University, Egypt \\ ${ }^{4}$ Assistant Professor in Operations Research, \\ faculty of graduate studies for statistical research, \\ Cairo University, Egypt
}

\begin{abstract}
Pension fund needs to produce a high-income return to face actuarial expectations of different kinds of benefits. An asset allocation management model of a pension fund must consider a large planning horizonbecause of its long-term obligations. Asset allocation controls solvency of the fund by suitable investments and contribution policies to secure the pensioners future liabilities. Artificial intelligence approaches given by experts and accepted by decision-makers, provide a powerful tool for describing the uncertainty.A portfolio optimization model is introduced based on variance minimization at a required return level that secures the fund againstinsolvency risk. This method uses anArtificial Bee ColonyOptimizationApproach to the mean-variance defined by Markowitz so that future returns of the stocks are predicted where the ability of AI to improve predictive and prescriptive financial forecasting processes will change the world of finance management.
\end{abstract}

Keywords: Pension Fund;Mean and Variance; Artificial Bee ColonyOptimizationand Insolvency risk.

\section{Introduction}

Pension fund must be periodic evaluated by actuaries and predict annual cash flow of income and liabilities (outcomes). The sponsor of plan take decisions at certain time, as investment decision to decide which assets allocated to attain a return enough to pay the participants' liabilities. The paper proposes model to assistance the decision maker to take this decision. Depending on earlier works of Markowitz [1], AI approaches which can help portfolio management teams analyze an investment operations andtrading history, for example, to identify key drivers of performance and potential behavioral biases. With such realtime feedback, portfolio managers may beable to avoid suboptimal decisions and improve their results over time. The paper proposes modify Markowitz model by adding new constraint that responsible for secure the pension fund towards insolvency risk. One of the most important choices DB plan investment committees will make is deciding which asset classes they will invest in, and how much they will invest in each one. Few other choices will have a greater impact on plan sponsors achieving their goals, and thus it constitutes a crucial element of a well-designed investment policy statement. While some investment decisions, such as manager selection, can be outsourced, in most cases the decision on how to appropriately allocate assets rests with the investment committee.

Pension funds are becoming fundamental tools in financial markets. Nowadays, pension fundinvestments represent a considerable percentage of financial market operations.In a general perspective, there are two extremely different ways to manage a pension fund. First, the pension fund can be managed through DefinedBenefit (DB) plans, where benefits are fixed in advance by the sponsor and contributions are 
initially set and subsequently adjusted in order to maintain the fund in balance.In other words, DB plan provides a guarantee by the pension plan or government that a pension will be paid based on a certain formula in which contribution may not be tied actually to benefits. Secondly, pension fund can be managed through DefinedContribution(DC) plans, where contributions are fixed and benefits depend on the returns on fund portfolio. In other words, DC plan provides a pension plan in which a periodic contribution is prescribed and the benefit depends on the contribution plus the investment return.

Many papersused the types of pension plans as:

Boulier et al. [2], Vigna and Haberman[3], Deelstra et al. [4], Battocchio and Menoncin[5], call in DC pension funds, Haberman and Sung [6], Chang [7], Haberman et al. [8], Taylor [9], Chang et al. [10], JosaFombellida and Rincón-Zapatero [11] and Josa-Fombellida and Rincón-Zapatero [12], in DB pension funds, and Cairns [13], in both types of plans. Yufei et al. [14]they consider the portfolio optimization problem for a pension fund consisting of various governmentand corporate bonds. And aims maximize the fund's cash position at the end of the time horizon, while allowing for the possibility of bond defaults.

Portfoliooptimization problem, which is sometimesreferred to as portfolio selection problem, is a wellknownproblem in management, economy and finance. Portfolioincludes different financial securities, such as bonds and stocksowned by an organization or by individuals. One of the main issues when dealing with portfolio optimization is risk. Investors are always trying to balance betweenportfolio's gains and risk. Thus, the goal is to select a portfoliowith minimum risk at defined minimal expected returns. Thisfurther means reducing non-systematic risks to zero [15].

Markowitz specified the trade-off facing the investor: risk versus expected return. The investment decisions are not simply which securities to own, but how to divide theinvestor's wealth amongst them. This is problem called "Portfolio Selection" hence the title of Markowitz's seminal article published in the 1952 issue of the Journalof Finance. He identifies all feasible portfolios that minimize risk (as measured by variance or standard deviation or other measurers) for a certain level of expected return andmaximize expected return for a certain level of risk.

Portfolio optimization problem is a multi-criteria optimization problem where the goal is to minimize risks, whilemaximizing returns. Unfortunately, this problem approach hasseveral shortcomings. First, this model is too simple for modeling real-world problem features.It does not capture all properties such as bounds of assets, transaction costs, costof management, etc. Second, it can be quite difficult togather enough data for risk and returns evaluation.Third, the estimation of return andcovariance from historical data is very prone to measurementerrors. Covariance matrix is used for defining the risk [16].

Portfolio optimization problem is being solved using differentof methods and techniques. Linear programming method, parametric quadratic programmingtechnique and integerprogramming were successfully applied to solving vagueportfolio selection problem.

In practice, market frictions,investor preferences, investment strategies,company policies of investment firmsetc., have resulted in complex objectives and constraints that have made portfolio optimizationproblemmore difficult, if not intractable. The complex mathematicalmodels defining the portfolio have found little help from traditional or analyticaltechniquesin their efforts to have optimal portfolios, forcing the need to look fornon-traditional algorithms and non-orthodox approaches from the broad disciplineof Computational Intelligence.

Fortunately, the emerging and fast-growing discipline of metaheuristics, a sub discipline of computational intelligence, has refreshingly becomes to be a solutions for all the ills of such of these famous problem models. Metaheuristics has not just turned out to be a viable alternative for solving intractable optimization problems, but in various cases has become to be the only alternative to solve the complex problem models concerned.Metaheuristic approaches represent efficient ways to deal with complexoptimization problems and are applicable to both continuous and combinatorialoptimization problems[17].

Nature-inspired Metaheuristics is a popular and activeresearch area which relies on natural systems for the solution of optimizationproblem models and is what has been applied to solve insolvency risk problem of pension fundby using portfolio optimizationmodelswhichdiscussed in this thesis. 
With the application of additional real-world constraints on the basic portfolio optimization formulation, the problem becomes harder for solving. In this case, traditional techniques and methods cannot generate satisfying results, and the use of heuristic and metaheuristic methods is more favorable. In some cases, problem characteristics, such as its size and constraints, or real world requirements, such as limited precision in estimating instance parameters or very limited computation time allowed, make traditional methods not particularly suitable for tackling large instances of the constrained portfolio selection problem, therefore researchers and practitioners have to resort to approximate algorithms and, in particular, to metaheuristics and hybrid techniques [18].

A metaheuristic is formally defined as an iterativegeneration process whichguides a subordinate heuristic bycombining intelligently different concepts for exploring andexploiting the search space. Thus, metaheuristics search for aperfect heuristics of a particular problem. Learning strategies areused to structure information in order to find efficiently nearoptimal solutions. Key point in metaheuristics is that they donot guarantee to find the optimal solution, but the satisfyingsolution in a reasonable amount of execution time.

Fieldsend et al. [19] present the concept of use metaheuristics instead of the traditional quadratic programming approach to portfoliooptimization because the difficultyof implement it when there are cardinalityconstraints (i.e. number of stocks in portfolio). Then recent approaches resolving this have used heuristic algorithmsto search for points on the cardinality constrained frontier.However, these can be computationally expensive when the practitionerdoes not know a priori exactly how many assets they may desire in aportfolio, or what scale of return and risk they wish to be exposed to without recourse to analyzing the actual trade-off frontier.

Researchers paid a special attention on developing approximation methods such as heuristic and metaheuristic algorithms in literature about portfolio selection and pension funding, suchas:

Evolutionary Algorithms (EA) and Swarm Intelligence (SI) approaches are two of the most preferred solution approaches for portfolio optimization. Metaxiotis\&Liagkouras[20] presented a literature review of multi-objective EA while Kalayci et al. [21] presented a recent review of genetic algorithms for portfolio optimization.

Retirement savings plans putting individuals “in the driver's seat” are proliferating around the globe. Many countries have already taken steps to create processes for participants that apply behavioral economics principles to balance personal engagement with automated decision making mechanisms. Artificial intelligencealready prevalent in many facets of our daily lives can be an ideal vehicle to build upon that progress by helping to create a more personalized participant experience than ever before. Doing so can enable better and more dynamic financial decisions by more engaged participants, thereby increasing retirement financial security. It can also empower plan fiduciaries to fulfill their duties more effectively and efficiently and to design plans that ultimately deliver better retirement outcomes for participants.

Josa-Fombellida and Rinc'on-Zapatero [22],study the optimal asset allocation problem of a DB pensionplan that operates in a financial market composed of risky assets whose prices are constantelasticity variance processes.

In this article modifies Markowitz's model by adding new constraint that responsible for secure the pension fund against insolvency risk i.e. ability for cover all participant's liabilities along horizon and use ABCapproachfor tackling large instances of the constrained portfolio selection problem.

The paper is organized as follows. The second section shows important definitionsthatuseful for the problem. The third section showsthe proposed model of the problem. The fourthsectionshows the fundamentals of $\mathrm{ABC}$ algorithm. The fifth sectionpresentsthe problem formulation and data set for the experiments andnumerical example.Finally, The sixth section presents a conclusion.

\section{Definitions}




\section{Definition1. The fundamental of the portfolio variance}

By generalized variance is to numbers $R_{1}, \ldots \ldots, R_{n}$ with constants $\lambda_{1}, \ldots \ldots, \lambda_{n} \in \mathrm{R}$, the definition can be obtained as:

$$
\begin{gathered}
\operatorname{Var}\left(\lambda_{1} R_{1}+\lambda_{2} R_{2}+\ldots \ldots \ldots \ldots+\lambda_{n} R_{n}\right)= \\
\lambda_{1}^{2} \operatorname{Var}\left(R_{1}\right)+\lambda_{2}^{2} \operatorname{Var}\left(R_{2}\right)+\ldots \ldots+\lambda_{n}^{2} \operatorname{Var}\left(R_{n}\right)+2\left|\lambda_{1} \lambda_{2}\right| \operatorname{Cov}\left(R_{1}, R_{2}\right)+\ldots+2\left|\lambda_{n-1} \lambda_{n}\right| \operatorname{Cov}\left(R_{n-1}, R_{n}\right)= \\
\sum_{i=1}^{n} \lambda_{i}^{2} \operatorname{Var}\left(R_{i}\right)+2 \sum_{i \neq j=1}^{n}\left|\lambda_{i} \lambda_{j}\right| \operatorname{Cov}\left(R_{i}, R_{j}\right)
\end{gathered}
$$

$\operatorname{Cov}\left(R_{i}, R_{j}\right)$ : The covariance of numbers $R_{i}$ and $R_{j}$

\section{Definition2.Markowitz's model:}

$$
\operatorname{Min} \operatorname{Var}\left(R_{p}\right)
$$

Subject to

Where

$$
\begin{aligned}
& \mathrm{E}\left(R_{p}\right) \geq \boldsymbol{K} ; \\
& \sum_{\mathrm{i}=1}^{\mathrm{n}} \mathrm{x}_{\mathrm{i}}=1 ; \\
& \mathrm{x}_{\mathrm{i}} \geq 0 ;
\end{aligned}
$$

$\mathrm{E}\left(R_{p}\right)$ : the expected portfolio return, $\mathrm{E}\left(R_{p}\right)=\sum_{\mathrm{i}=1}^{\mathrm{n}} \mathrm{x}_{\mathrm{i}} \mathrm{E}\left(R_{i}\right)$

$\operatorname{Var}\left(R_{p}\right)$ : The variance of portfolio,

$\operatorname{Var}\left(R_{p}\right)=\sum_{\mathrm{i}=1}^{\mathrm{n}} \mathrm{x}^{2}{ }_{\mathrm{i}} \operatorname{var}\left(R_{i}\right)+2 \sum_{i \neq j=1}^{n} \mathrm{x}_{i} \mathrm{x}_{j} \operatorname{Cov}\left(R_{i}, R_{j}\right)$

$\operatorname{Cov}\left(R_{i}, R_{j}\right)$ : The covariance of returns $R_{i}$ and $R_{j}$

$\mathrm{x}_{\mathrm{i}}$ : is money allocated percentage at asset $\mathrm{i}$

$\boldsymbol{K}$ : certain return

\section{Proposed model}

Let the portfolio consisting of $\mathbf{n}$ assets and operating over next time of one period, $\mathbf{M}$ denotes the fund's cash level at the start of the certain period, $\mathrm{R}_{\mathrm{i}}$ denote the return at the end of this period, $\mathbf{P}$ denote the total pension payments plus all additive payments related the plan to be made during this period and Cdenote the contribution to be made during this period obtained by actuaries. Hence we can write the proposed model as

$$
\text { Min } \operatorname{Var}\left(\mathrm{R}_{\mathrm{P}}\right)=\sum_{\mathrm{i}=1}^{\mathrm{n}} \operatorname{var}\left(\mathrm{R}_{\mathrm{i}}\right) \mathrm{x}^{2}{ }_{\mathrm{i}}+2 \sum_{\mathrm{j} \neq \mathrm{i}=1}^{\mathrm{n}} \operatorname{cov}\left(\mathrm{R}_{\mathrm{i}} ; \mathrm{R}_{\mathrm{j}}\right) \mathrm{x}_{\mathrm{i}} \mathrm{x}_{\mathrm{j}}
$$

Subject to

$$
\begin{aligned}
& \mathrm{E}\left(\mathrm{R}_{\mathrm{P}}\right)=\sum_{\mathrm{i}=1}^{\mathrm{n}} \mathrm{E}\left(\mathrm{R}_{\mathrm{i}}\right) * \mathrm{x}_{\mathrm{i}} \geq \boldsymbol{K} ; \\
& \left(1+\mathrm{E}\left(\mathrm{R}_{\mathrm{P}}\right) *(\mathrm{M})+\mathrm{C}-\mathrm{P} \geq 0 ; \quad\right. \text { (insolvency risk) } \\
& \sum_{\mathrm{i}=1}^{\mathrm{n}} \mathrm{x}_{\mathrm{i}}=1 ; \\
& \alpha_{\mathrm{i}}<\mathrm{x}_{\mathrm{i}}<\quad \beta_{\mathrm{i}} \mathrm{i}=1,2, \ldots, \mathrm{n} \\
& \mathrm{x}_{\mathrm{i}} \geq 0 ; \quad \mathrm{i}=1,2, \ldots, \mathrm{n} \text { (Short sell not allowed) }
\end{aligned}
$$

Where

$$
\mathrm{E}\left(R_{P}\right) \text { : Expectation of return of portfolio }
$$


$\mathrm{V}\left(R_{P}\right)$ : Variance of return (risk) of portfolio

$K$ : Required return satisfied the balance in pension plan and secures the fund against insolvency $\operatorname{cov}\left(R_{i} ; R_{j}\right)$ : Covariance between returns of assets $\mathrm{i}, \mathrm{j}$

M: Fund's reserve of pension plan

C: Contributions paid by scheme's participants

P: Grantees benefits paid by pension scheme plus all administrative expenses

$x_{i}$ : Proportion at assets i

$\alpha_{\mathrm{i}} \quad$ : Lower bound of asset $\mathrm{i}$

$\beta_{\mathrm{i}}$ : Upper bound of asset $\mathrm{i}$

The adding constraint $\left(1+\mathrm{E}\left(\mathrm{R}_{\mathrm{P}}\right)\right) *(\mathrm{M})+\mathrm{C}-\mathrm{P} \geq 0$ in detail :

This constraint meaning that all money in the fund $(\mathrm{M})$ at start of period after investment optimization i.e. (1+ $\left.\mathrm{E}\left(\mathrm{R}_{\mathrm{P}}\right)\right)^{*}(\mathrm{M})$ plus yearly contributions $(\mathrm{C})$ must be cover all liabilities plus all administrative expenses $(\mathrm{P})$.

The optimized portfolio is found by minimizing the variance (risk) for a certain target return level, which determined by actuary’ mathematics rules,that reserve the pension fund from insolvency risk.

\section{Constrained ABC algorithm}

ABC is well-known population based swarm intelligencemetaheuristic. It is inspired by the foraging behavior of bee swarms in nature. This approach firstly proposed byKaraboga[23], and developed by Karaboga andBasturk[24].A serious difference between the ABC and other swarmintelligence algorithms is that in the ABC algorithm thepossible solutions represent as food sources, notindividuals (bees). In other algorithms, like PSO, eachpossible solution represents an individual of the swarm. In theABC algorithm the quality of solution is represented as fitnessof a food source. Fitness is calculated by using objectivefunction of the problem.

In $\mathrm{ABC}$ metaheuristic, there are three types of artificial bees (agents):

i. Employed bees,

ii. Onlookers bees and

iii. Scouts bees.

Half of the colony is employed bees. The relation between employed bee and the food source is oneto-one, and that means that there is only one employed bee per each food source. If a food source becomes abandoned, employed bee that is mapped to that food source becomes a scout, and as soon as scout finds a new food source, it again becomes employed bee. In the ABC algorithm onlookers and employed bees carry out the exploitation procedures in the search space, while the scouts control the exploration procedures.

In the case of bees, the basic properties on which self-organization rely are as follows:

- Positive feedback: As the nectar amount of food sources increases, the number of onlookers visiting them increases.

- Negative feedback: The exploration procedures of a food source abandoned by bees are stopped.

- Fluctuations: The scouts carry out random search procedures for discovering new food sources.

- Multiple interactions: Bees share their information about food source positions with their nest mates on the dance area [15].

The framework of $\mathrm{ABC}$ is presented in Fig. 1, where there are three groups of bees constituting the whole colony employed, onlookers, and scouts bees. Firstly, employed bees start searching for food sources and swap the information they gather to onlooker bees. Then, onlookers make a decision and select some valuable food sources for further search. If the quality of the food source is not improved after a certain predetermined time, the employed bee will abandon it and turns into a scout. Then, thescout searches a new food source and the algorithm execute as mentioned next. 


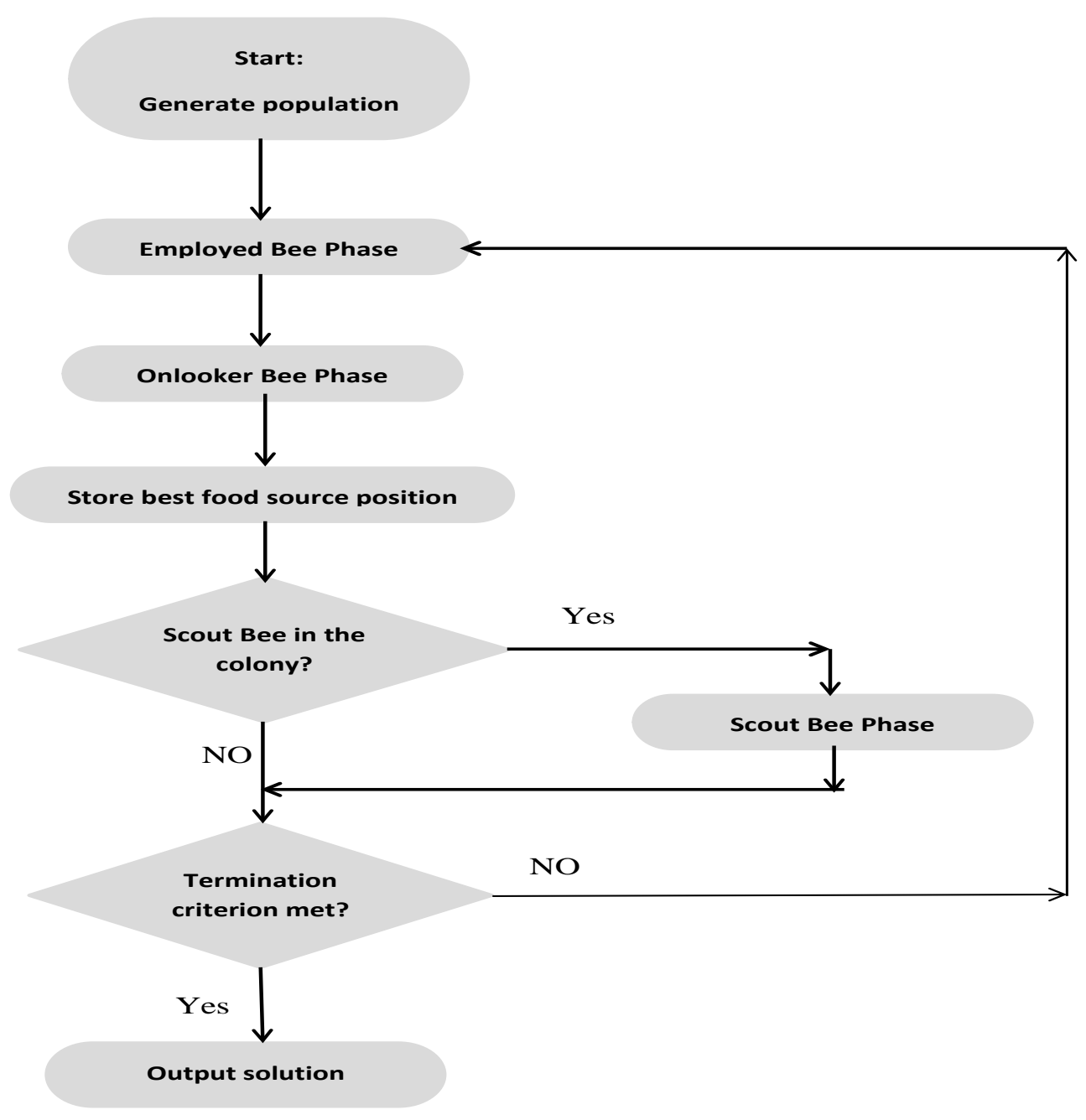

Figure 1. The Flowchart of Artificial Bee Colony Algorithm

ABC algorithm, as an iterative algorithm, starts byassociating each employed bee with randomly generated foodsource (solution). Each solution $x_{i}(\mathrm{i}=1,2, \ldots, \mathrm{SN})$ is a Ddimensional vector, where SN denotes the size of the population. Initial population of randomly generated solutionis created using:

$$
x_{i, j}=l b_{j}+\operatorname{rand}(0,1) *\left(u b_{j}-l b_{j}\right)
$$

In each iteration, each employed bee detects a foodsource in its neighborhood, and evaluates its nectar amount (fitness). Discovery of a new, neighborhood solution ismodeled with the following expression:

$$
v_{i, j}=\left\{\begin{array}{c}
x_{i, j}+\emptyset *\left(x_{i, j}-x_{i, j}\right) ; \text { feasible } \\
x_{i, j} ; \text { otherwise }
\end{array}\right.
$$

Where $x_{\mathrm{i}, \mathrm{j}}$ is $\mathrm{j}^{\text {th }}{ }^{\text {th }}$ parameter of the old solution $\mathrm{i}, x_{\mathrm{k}, \mathrm{j}}$ is $\mathrm{j}^{\text {-th }}$ parameter of a neighbor solution $\mathrm{k}$, $\emptyset$ is a random numberbetween -1 and 1 problemas:

Karaboga\&Basturk[25] present a pseudo-code of the ABC metaheuristic for constrainedoptimization 
1. Initialize the population

2. Evaluate the random population

3. Cycle=1

4. Repeat

5. Make new solutions for the employed beesby using Equation (2) and evaluate them

6. Apply selection process based on feasibility and fitness function.

7. Calculate the probability values $p_{i}$ for thesolutions $x_{i}$, using fitness of the solutions

8. For each onlooker bee, produce a newsolution $v_{i j}$ by eq. (2) in theneighborhood of the solution selecteddepending on value of $p_{i}$ and evaluate it

9. Apply selection process between $v_{i}$ and $x_{i}$ based greedy selection.

10. Determine the abandoned solutions by using the "limit" parameter for the scout, if they exist, replace them with new randomlyproduced solutions by eq. (1).

11. Memorize the best solution achieved so far.

12. Cycle $=$ Cycle+1

13. Until cycle $=\mathrm{MCN}$

We also note that in this case the fitness calculated using:

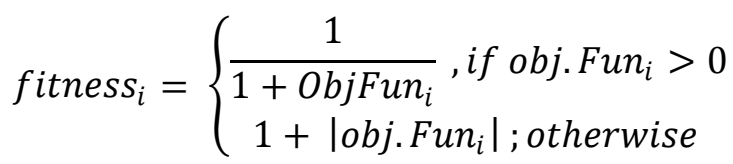

WhereObjFun $i$ is the value of objective function which is thesubject of optimization.

\section{Problem formulation and data set for the experiments}

This thesis used simplehistorical data set likein Zaher et al. [26]. The data encompasseshistorical return of a ninestocks portfolio of a period of nineyears (2013-2021). Data set is shown in Table 1.

We can evaluate participants of some Egyptian funds at 1/1/2021 and its data and results as following:

Determinethe required rate of return secure the fund and collecting data as:

$\mathrm{M}$ (reserve of pension fund at start year) $=50000000 \mathrm{~L}$. E.;

$\boldsymbol{K}($ the required rate of return secure the fund $)=0.09$;

$\mathrm{P}$ (all expected liabilities at first year) $=107330383$;

C (expected contribution at first year) $=47449742$;

The actuary's results:

Table 1. Cash flow for the expected liabilities and contributions

\begin{tabular}{|c|c|c|}
\hline Years & Income & All liabilities \\
\hline 2021 & 47449742 & 107330383 \\
\hline
\end{tabular}

Table 1 illustrate the promised benefits for the participants and their future contributions, from the evaluation's results sponsor's decisions should be invest the surplus to attain the required rate of return to satisfy fund's balance. 
In this part we can point to the case study Egyptian Stock Exchange (EGX). Table 2 shows these stocks. All data in this table consisting of the closing values of nine stocks from 1.2013 to 1.2021 are taken from the official web site of EgyptianStock Sxchange prices, sa.investing.com, on a yearly basis total of 9observation periods.

Table2. Closed market value of the assets

\begin{tabular}{|c|c|c|c|c|c|c|c|c|c|}
\cline { 2 - 10 } \multicolumn{1}{c|}{} & Assets & \multicolumn{10}{c|}{} \\
\hline date & COMI & QNBA & VODE & OREG & EAST & ABUK & ETEL & GTHE & SWDY \\
\hline $01 / 2013$ & 15.11 & 7.51 & 86.9 & 15.93 & 2.31 & 8.4 & 14.5 & 4.42 & 2.05 \\
\hline $01 / 2014$ & 21.52 & 6.93 & 72.08 & 15.99 & 2.84 & 10.84 & 14.84 & 5.18 & 3.17 \\
\hline $01 / 2015$ & 35.33 & 8.97 & 80.06 & 19.25 & 4.89 & 10.68 & 12.21 & 4.65 & 5.07 \\
\hline $01 / 2016$ & 25.41 & 8.98 & 35.55 & 10.44 & 3.38 & 9.29 & 6.07 & 1.80 & 3.53 \\
\hline $01 / 2017$ & 61.15 & 13.85 & 66.77 & 10.61 & 8.83 & 6.36 & 12.30 & 7.08 & 8.40 \\
\hline $01 / 2018$ & 62.67 & 19.43 & 112.72 & 34.12 & 20.57 & 29.90 & 13.32 & 6.80 & 15.64 \\
\hline $01 / 2019$ & 66.42 & 20.21 & 108.05 & 13.01 & 16.86 & 23.30 & 13.99 & 4.52 & 17.68 \\
\hline $01 / 2020$ & 85.08 & 23.25 & 137.77 & 22.06 & 15.01 & 21.02 & 12.34 & 5.08 & 11.28 \\
\hline $01 / 2021$ & 63.34 & 17.31 & 130.00 & 18.56 & 14.80 & 23.45 & 11.66 & 5.08 & 10.17 \\
\hline
\end{tabular}

Table 3. The returns of the assets

\begin{tabular}{|c|c|c|c|c|c|c|c|c|c|}
\cline { 2 - 10 } \multicolumn{1}{c|}{} & Assets & \multicolumn{10}{c|}{} & \multicolumn{2}{l|}{ date } & COMI & QNBA & VODE & OREG & EAST & ABUK & ETEL & GTHE & SWDY \\
\hline $01 / 2014$ & 6.41 & -0.58 & -14.82 & 0.06 & 0.53 & 2.44 & 0.34 & 0.76 & 1.12 \\
\hline $01 / 2015$ & 13.81 & 2.04 & 7.98 & 3.26 & 2.05 & -0.16 & -2.63 & -0.53 & 1.90 \\
\hline $01 / 2016$ & -9.92 & 0.01 & -44.51 & -8.81 & -1.51 & -1.39 & -6.14 & -2.85 & -1.54 \\
\hline $01 / 2017$ & 35.74 & 4.87 & 31.22 & 0.17 & 5.45 & -2.93 & 6.23 & 5.28 & 4.87 \\
\hline $01 / 2018$ & 1.52 & 5.58 & 45.95 & 23.51 & 11.74 & 23.54 & 1.02 & -0.28 & 7.24 \\
\hline $01 / 2019$ & 3.75 & 0.78 & -4.67 & -21.11 & -3.71 & -6.60 & 0.67 & -2.28 & 2.04 \\
\hline $01 / 2020$ & 18.66 & 3.04 & 29.72 & 9.05 & -1.85 & -2.28 & -1.65 & 0.56 & -6.40 \\
\hline $01 / 2021$ & -21.74 & -5.94 & -7.77 & -3.50 & -0.21 & 2.43 & -0.68 & 0.00 & -1.11 \\
\hline
\end{tabular}

Table 3 show the return's values of these nine stocks by changes in their closed values as observations along 9 years.

Table 4.the rate of return of assets

\begin{tabular}{|c|c|c|c|c|c|c|c|c|c|}
\cline { 2 - 10 } \multicolumn{1}{c|}{} & Assets & \multicolumn{10}{c|}{ date } & COMI & QNBA & VODE & OREG & EAST & ABUK & ETEL & GTHE & SWDY \\
\hline $01 / 2014$ & 0.42 & -0.08 & -0.17 & 0.00 & 0.23 & 0.29 & 0.02 & 0.17 & 0.55 \\
\hline $01 / 2015$ & 0.64 & 0.29 & 0.11 & 0.20 & 0.72 & -0.01 & -0.18 & -0.10 & 0.60 \\
\hline $01 / 2016$ & -0.28 & 0.00 & -0.56 & -0.46 & -0.31 & -0.13 & -0.50 & -0.61 & -0.30 \\
\hline $01 / 2017$ & 1.41 & 0.54 & 0.88 & 0.02 & 1.61 & -0.32 & 1.03 & 2.93 & 1.38 \\
\hline $01 / 2018$ & 0.02 & 0.40 & 0.69 & 2.22 & 1.33 & 3.70 & 0.08 & -0.04 & 0.86 \\
\hline $01 / 2019$ & 0.06 & 0.04 & -0.04 & -0.62 & -0.18 & -0.22 & 0.05 & -0.34 & 0.13 \\
\hline $01 / 2020$ & 0.28 & 0.15 & 0.28 & 0.70 & -0.11 & -0.10 & -0.12 & 0.12 & -0.36 \\
\hline $01 / 2021$ & -0.26 & -0.26 & -0.06 & -0.16 & -0.01 & 0.12 & -0.06 & 0.00 & -0.10 \\
\hline
\end{tabular}

Table 4 show the return's rates of these nine stocks by dividing their values on closed market values of each stock as observations along 9 years.

The mean return on each asset and covariance matrix is given in Tables 5 and 6 respectively. 
Table 5.the mean of return of assets

\begin{tabular}{|c|c|}
\hline Asset & mean of return \\
\hline COMI & 0.29 \\
\hline QNBA & 0.14 \\
\hline VODE & 0.14 \\
\hline OREG & 0.24 \\
\hline EAST & 0.41 \\
\hline ABUK & 0.42 \\
\hline ETEL & 0.04 \\
\hline GTHE & 0.27 \\
\hline SWDY & 0.34 \\
\hline
\end{tabular}

Table 5.the covariance matrix of returns of assets

\begin{tabular}{|c|c|c|c|c|c|c|c|c|c|}
\hline Cov(w1;w2) & COMI & QNBA & VODE & OREG & EAST & ABUK & ETEL & GTHE & SWDY \\
\hline COMI & 0.305 & 0.103 & 0.167 & -0.001 & 0.281 & -0.176 & 0.196 & 0.529 & 0.258 \\
\hline QNBA & 0.103 & 0.070 & 0.100 & 0.117 & 0.162 & 0.112 & 0.070 & 0.177 & 0.118 \\
\hline VODE & 0.167 & 0.100 & 0.217 & 0.253 & 0.294 & 0.257 & 0.162 & 0.371 & 0.208 \\
\hline OREG & -0.001 & 0.117 & 0.253 & 0.800 & 0.360 & 1.073 & 0.030 & 0.001 & 0.175 \\
\hline EAST & 0.281 & 0.162 & 0.294 & 0.360 & 0.534 & 0.456 & 0.238 & 0.572 & 0.416 \\
\hline ABUK & -0.176 & 0.112 & 0.257 & 1.073 & 0.456 & 1.798 & -0.012 & -0.253 & 0.256 \\
\hline ETEL & 0.196 & 0.070 & 0.162 & 0.030 & 0.238 & -0.012 & 0.193 & 0.460 & 0.213 \\
\hline GTHE & 0.529 & 0.177 & 0.371 & 0.001 & 0.572 & -0.253 & 0.460 & 1.225 & 0.487 \\
\hline SWDY & 0.258 & 0.118 & 0.208 & 0.175 & 0.416 & 0.256 & 0.213 & 0.487 & 0.372 \\
\hline
\end{tabular}

\subsection{Problem formulation}

The goal is to select weights of the each asset in theportfolio in order to minimize the portfolio's risk at certain portfolio's return. We add a certain constraint that control of solvency of pension fund problem with another constraints. The expected return of each individual security iispresented as follows:

$$
E\left(W_{i}\right)=W_{i} R_{i}
$$

Where $w_{i}$ denotes the weight of individual asset $\mathrm{i}$, and $R_{\mathrm{i}} \mathrm{isthe}$ expected return of $\mathrm{i}$. Total expected return of the portfolioP can be formulated as follows:

$$
E(\mathrm{P})=\sum_{i=1}^{n} E\left(W_{i}\right)
$$

Wheren is the number of securities in the portfolio P. In our problem formulation, first goal is to satisfying portfolio's expected returnand the weight of securities are lies in their bounds and thus, the expression shown in(5) is greater than the required return that secure the fund towards insolvency risk where the fund's risk should be minimized.

The objective function of the portfolio variance (risk) ispresented as a polynomial of second degree which consider as the insolvency risk of pension fund can be present as:

Min $\operatorname{Var}\left(\mathrm{R}_{\mathrm{P}}\right)=\sum_{\mathrm{i}=1}^{\mathrm{n}} \operatorname{var}\left(\mathrm{R}_{\mathrm{i}}\right) w^{2}{ }_{\mathrm{i}}+2 \sum_{\mathrm{j} \neq \mathrm{i}=1}^{\mathrm{n}} \operatorname{cov}\left(\mathrm{R}_{\mathrm{i}} ; \mathrm{R}_{\mathrm{j}}\right) w_{i} w_{j}$

Wherevar $\left(R_{i}\right)$ is variance of asset $i$, and $\operatorname{cov}\left(R_{i}, R_{j}\right)$ iscovariance between securities $i$ and $j$. 


\subsection{ABC parameters setup}

In this subsection, we present experimental results fortesting $A B C$ metaheuristics for pensionfund'srisk optimization problem.(Seesubsection 5.1 for problem formulation). All tests wereperformed on Intel Core i5 processor with 4GBof RAM memory, Windows 10 x64 operating system andVisual Studio 2021 with .NET 4.5 Framework.

Solution number SN was set to 50, and maximum cyclenumber MCN was set to 1000 , yielding total of 50,000 objective function evaluations $(50 * 1000)$.

Limit parameter is calculated using:

$$
\text { Limit }=\frac{\mathrm{MCN}}{\mathrm{SN}}(7)
$$

Thus, in this case, limit is set to 20 (1000/50). Accordingto ABC experimental studies, limit calculated with (7)established optimal balance between exploitation andexploration [23].

Since the portfolio of pension fund's reservecontains of nine stocks, dimension D of aproblem is 9.Each food source in the population is 9-dimensional vector. In initialization phase, food source $x$ isgenerated using the followingexpression:

$$
x_{i}=w_{i}^{\text {low }}+\operatorname{rand}(0,1) *\left(w_{i}^{\text {up }}-w_{i}^{\text {low }}\right)
$$

Where rand $(0,1)$ is a random number uniformly distributedbetween 0 and 1.

\subsection{Experimental results}

By writing model's code and have results.

The optimal allocation for the reserve of pension fund to secure the fund and reserve the balance for the pension's plan for the nine assets is:-

Table 6.the result

\begin{tabular}{|c|c|c|c|c|c|c|c|c|c|}
\hline Assets & COMI & QNBA & VODE & OREG & EAST & ABUK & ETEL & GTHE & SWDY \\
\hline weights & 0.4 & 0.4 & 0 & 0.11 & 0.01 & 0.06 & 0.02 & 0 & 0 \\
\hline
\end{tabular}

Table6 illustrate the weights that satisfy the constraint and the objective function has minimum value. Then sponsor's objectives are occur where risk (variance) is minimized which is objective function and equal 0.14.

\section{Conclusion}

In this paper, $\mathrm{ABC}$ algorithm for pension fund constrained portfoliooptimization problem was presented. The implementation ofthe $\mathrm{ABC}$ for this problem was not found in the literature. Thealgorithm was tested on a set of nine stocks portfolio.

The results of the investigation reported in this paper showthat the $\mathrm{ABC}$ swarm intelligence metaheuristic has potentialfor solving this problem.

ABC was applied only to the basic portfolio optimizationproblem definition. There is a large potential for applyingmetaheuristic techniques to this class ofproblems as pension fund portfolio problems, becausethey appear not to be investigated enough. In the subsequentwork, original, as well as the version of the $\mathrm{ABC}$ willbe applied to the extended-mean variance after adding the constraint which control of the insolvency risk of pension fund, and other pension funds models. Also, other swarm intelligencemetaheuristics will be applied to various pension fund problem models and definitions.

We have analyzed the management of a pension funding process of a DB pension plan when the short interest rate is the yearly model. Yearly insolvency risk may be solved analytically when the benefits process is a determined under a suitable selection of the technical interest rate and actuary determine the required return ratethat does not exposepensionfund to insolvency risk.

The components of the optimal portfolio investments in risky and riskless assets are the sum of all terms, and face the actuarial liability, depending on parameters of the randomness of benefits, all expenses and contributions where interest rate determined by actuaries. 
We have done a case study of the pension fund and have all required data to show some properties of the model. The decision maker would check the fund's finance status every short certain period.

A portfolio optimization method which minimizes the variance of the portfolio is introduced and this method is applied to the 9 well known stocks of Egypt Stock Market. With its background this method has some serious advantages compared to the classical MV optimization which is introduced by Markowitz 69 years ago. Firstly, the required return for balance of pension's fund can check short certain period and can reallocate if the required not satisfied. Secondly, the portfolio managers can add their subjective opinions to the model with the help of change of the parameters of ABC algorithm. Thirdly, this method does not require the limitations of classical MV optimization which are listed in detail of the classical MV optimization.

\section{References}

[1] Markowitz, H. Portfolio selection. J. Finance,(1952); 7 (1), 77-91.

[2]Boulier JF, Huang S, Taillard G. Optimal management under stochastic interest rates: the case of a protected defined contribution pension fund. Insurance: Mathematics and Economics,(2001), 28:173-89.

[3] Vigna E, Haberman S. Optimal investment strategy for defined contribution pension schemes. Insurance: Mathematics and Economics,(2001), 28:233-62.

[4] Deelstra G, Grasselli M, Koehl PF. Optimal investment strategies in a CIR model. Journal of Applied Probability,(2000), 37:93646.

[5] Battocchio P, Menoncin F. Optimal pension management in a stochastic framework. Insurance: Mathematics and Economics (2002), 34:79-95.

[6] Haberman S, Sung JH. Dynamics approaches to pension funding. Insurance: Mathematics and Economics,(1994), 15:151-62.

[7] Chang SC. Optimal pension funding through dynamic simulations: the case of Taiwan public employees' retirement systems. Insurance: Mathematics and Economics,(1999), 24:187-99.

[8] Haberman S, Butt Z, Megaloudi C. Contribution and solvency risk in a defined benefit pension scheme. Insurance: Mathematics and Economics,(2000), 27:237-59.

[9] Taylor G. Stochastic control of funding systems. Insurance: Mathematics and Economics,(2002), 30:323-50.

[10] Chang SC, Tzeng LY, Miao JCY. Pension funding incorporating downside risks. Insurance: Mathematics and Economics 2003; 32:217-28.

[11] Josa-Fombellida R, Rincón-Zapatero JP. Minimization of risks in pension funding by means of contribution and portfolio selection. Insurance: Mathematics and Economics, (2001),29:35-45.

[12]Josa-Fombellida R, Rincón-Zapatero JP. Optimal management of risks in defined-benefit stochastic pension funds. Insurance: Mathematics and Economics, (2004), 34:489-503.

[13] Cairns AJG. Some notes on the dynamics and optimal control of stochastic pension fund models in continuous time. ASTIN Bulletin,(2000),30: 19-55.

[14] Yufei S., Grace A., Ryan L., Kok L. Chance-constrained Optimization for Pension Fund Portfolios in the Presence of Default Risk, European Journal of Operational Research,(2016).

[15] Bacanin, N., Tuba, M., \&Pelevic, B. Constrained portfolio selection using artificial bee colony (ABC) algorithm. International Journal of Mathematical Models and Methods In Applied Sciences,(2014), 8(1), 190-198.

[16] Di Tollo, G., \&Roli, A. Metaheuristics for the portfolio selection problem. International Journal of Operations Research, 2008. 5(1), 13-35.

[17] Yang, X.S., Chien, S.F. and Ting, T.O. Computational Intelligence and Metaheuristic Algorithms with Applications. Scientific World Journal, (2014), 1-4.

[18] Blum, C., \&Roli, A. Metaheuristics in combinatorial optimization: Overview and conceptual comparison. ACM computing surveys (CSUR), (2003). 35(3), 268-308.

[19] Fieldsend, J. E., Matatko, J., \&Peng, M. Cardinality constrained portfolio optimization. In International Conference on Intelligent Data Engineering and Automated Learning, (2004), (pp. 788-793). Springer, Berlin, Heidelberg.

[20] Metaxiotis, K., \&Liagkouras, K. Multiobjective evolutionary algorithms for portfolio management: A comprehensive literature review. Expert Systems with Applications, (2012), 39(14), 11685-11698.

[21] Kalayci, C. B., Ertenlice, O., Akyer, H., \&Aygoren, H. An artificial bee colony algorithm with feasibility enforcement and infeasibility toleration procedures for cardinality constrained portfolio optimization. Expert Systems with Applications, (2017), 85, 61-75.

[22] Josa-Fombellida R., López-Casado P., Rincón-Zapatero J.P. Portfolio optimization in a defined benefit pension plan where the risky assets are processes with constant elasticity of variance. Insurance: Mathematics and Economics (2018).

[23] Basturk B, Karaboga D. An artificial bee colony (ABC) algorithm for numeric function optimization. In: Proceedings of the IEEE swarm intelligence symposium,(2006), pp 12-14

[24] Karaboga, D., \&Basturk, B. A powerful and efficient algorithm for numerical function optimization: artificial bee colony (ABC) algorithm. Journal of global optimization,(2007), 39(3), 459-471.

[25] Karaboga, D., \&Basturk, B. On the performance of artificial bee colony (ABC) algorithm. Applied soft computing,(2008), 8(1), 687-697.

[26] Zaher H., Saeid N. and Safwat S. “Asset Allocation Management to Secure Pension Fund in Fuzzy Environment”. Proceedings of the Annual 53rd Conference on Statistics, Computer Science and Operation Research. ISSR (2018), 20-31. 